\title{
The relationship between learning styles and affinity for concept mapping among graduate nursing students
}

\author{
Erica Sciarra * \\ The graduate nursing program, Walden University, Minneapolis, United States
}

Received: November 2, 2015

DOI: $10.5430 /$ jnep.v6n5p28
Accepted: December 14, 2015 Online Published: January 4, 2016

URL: http://dx.doi.org/10.5430/jnep.v6n5p28

\begin{abstract}
This pilot study was conducted using a convenience sample of graduate nursing students to explore the relationship between learning styles and the affinity for concept mapping as a tool to understand complex topics. The findings suggested all identified learning styles acknowledged the usefulness of concept mapping in understanding complex concepts. However, although most participants deemed concept mapping as helpful in understanding complex concepts, $90 \%$ stated they did not routinely create them when not required to do so.
\end{abstract}

Key Words: Concept mapping, Graduate nursing students, Learning styles

\section{BACKGROUND}

A literature review was conducted to identify research studies investigating the efficacy of concept mapping among nursing students. A search was also conducted to gain more insight into the preferred method of knowledge obtainment according to learning styles. Computerized searches of the CINAHL database was performed using the keywords: Concept maps and nursing students, learning styles, and learning styles of nursing students. The goal of the literature search was to locate research regarding the efficacy of concept mapping in promoting knowledge obtainment and critical thinking skills. Additionally, the researcher desired to gain further insight into which active learning modalities are favored by various learning styles.

\subsection{Concept mapping}

Concept mapping is described as a visual representation of complex topics. Essentially, relationships are depicted within a schematic and linked together by various symbols. ${ }^{[1]} \mathrm{Re}-$ search has proven concept mapping to be particularly successful in helping nursing students develop their conceptual and critical thinking skills. ${ }^{[2]}$ Critical thinking is necessary among the healthcare professions because it guides decision making in critical circumstances where rote knowledge may not apply. Jaafarpour, Azami and Mozafari ${ }^{[3]}$ conducted a $^{[3}$ study in which 64 nursing students were divided into two methods of study: quizzes and concept mapping development. After eight weeks each group was given a cumulative exam. The mean scores of the group who participated in concept mapping were higher than the traditional quiz method.

Nursing as a profession traditionally requires caregivers to have a vast amount of knowledge regarding a variety of topics. Concept mapping is a particularly useful strategy for the synthesis of complex topics, promotion of critical and abstract thinking. Harrison and Gibbons ${ }^{[4]}$ conducted 12 semi structured interviews with nursing students and found that nursing students convey a positive attitude towards concept mapping when clear direction is given and they are open

\footnotetext{
${ }^{*}$ Correspondence: Erica Sciarra, DNP, APN-C, CNE; Email: elk1180@ optonline.net; Address: The graduate nursing program, Walden University, Minneapolis, United States.
} 
minded and motivated. Nursing programs utilize various teaching methods to cultivate critical thinking among its students due to nature of the content that must be learned.

Research supports the use of multiple active teaching strategies to promote knowledge obtainment. Pudelko, Young, Lamare and Charlin ${ }^{[5]}$ found that when meaningful feedback is provided to expand upon complex topics, concepts mapping is very beneficial as an adjunctive teaching method. Concept mapping can be effective when integrated as a complement to traditional teaching styles.

\subsection{Learning styles}

Concept mapping has been linked to various theories of knowledge obtainment such as Ausubel's theory of meaningful learning. ${ }^{[4]}$ The participants were required to self-identify which style they are most akin to being: visual, auditory, reading/writing, kinesthetic or other. Visual learning is described as learning best by seeing visual aids to support knowledge obtainment. Auditory learners learn through active listening of presented information. Readers/Writers respond best to either reading the information repeatedly or writing it out. Kinesthetic learners learn best by actual hands on learning.

\subsection{Purpose}

The purpose of this descriptive pilot study was to describe the relationship between learning style and the use of concept mapping. The research question that guided this study was: is there a relationship between learning style and whether the learner feels concept mapping helps make difficult concepts easier to understand?

\section{METHOD}

\subsection{Setting and sample}

The convenience sample of this pilot study was obtained from a participant pool of students who volunteered to be a part of research studies being conducted at the University. The inclusion criteria was students who were registered in the participant pool and were part of the Graduate Nursing program. Graduate nursing students were chosen due to the fact they were required to complete concept maps as part of their course work. Exclusion criteria was students were not part of the university's participant pool and not currently enrolled in the graduate nursing program.

\subsection{Instruments}

Participants were asked to self-identify their learning style by visiting http://varklearncom.digiwebhosting.co $\mathrm{m} /$ the-vark-questionnaire/. The VARK questionnaire is a 16-question tool designed by Neil D. Fleming to identify the users learning style being Visual, Auditory, Read/Write Published by Sciedu Press and Kinesthetic (C) Copyright Version 7.3 (2001) held by Neil D. Fleming, Christchurch, New Zealand). Validity was established using multimethod factor analysis in additional to correlated method analysis. ${ }^{[6]}$ Leite, Svinke, and Shi ${ }^{[6]}$ also established reliability by demonstrating adequate reliability statistics.

The second instrument was created by the researcher and contained 7 questions related to the student's self-identified learning style, the student's attitude towards concept mapping, and the student's use of concept mapping when not required. Demographic data was also collected from this instrument.

\subsection{Data collection}

Data collection began after university IRB approval was obtained. An abstract regarding the purpose of the study was placed on the University's Research platform where students can access various studies available for participation at the University. Students were able to voluntarily and anonymously choose to participate in the study. Students were required to view the consent for participation prior to answering questions ensuring the voluntary nature of participation as well as the lack of compensation for completing the study. No identifying information was collected from the student.

After reading the abstract, participants were requested to self-identify their learning style by completing the VARK ${ }^{\mathrm{TM}}$ questionnaire via linking to the VARK website. Permission to refer participants to this website to obtain their learning style was granted by the instruments developer (C) Copyright Version 7.3 (2001) held by Neil D. Fleming, Christchurch, New Zealand).

After completing the VARK questionnaire participants were redirected to Surveymonkey. com to complete a 7-question survey which asked them to self-identify their learning style based on their VARK score as well as their feelings regarding whether concept mapping helped increase their understanding of complex topics. The survey also questioned the participants as to whether they routinely create concept maps when not required to facilitate learning. Demographic information was also collected from each participant.

\section{Results}

The sample consisted of 11 participants. One person viewed the survey but did not answer any questions. Of the ten that completed the study, all of them were women $(n=10)$. Approximately $70 \%$ were Caucasian $(n=7)$ and the remaining participants were African American $(n=3)$. The ages of the participants were $20 \%$ aged $30-39(\mathrm{n}=2), 50 \%$ aged 40-49 $(n=5)$, and 30\% 50-59 $(n=3)$. Of the participants, 
$20 \%$ identified their learning style as being a Visual learner $(\mathrm{n}=2), 30 \%(\mathrm{n}=3)$ identified their learning style as Reading/Writing, 30\% $(\mathrm{n}=3)$ identified their learning style as being Kinesthetic, and 20\% ( $\mathrm{n}=2)$ identified their learning style as other. None of the respondents identified as auditory learners. $90 \%$ of the participants stated that concept maps are helpful in understanding complex topics. However, $10 \%$ of participants stated they develop their own concept maps to help them understand a concept when it is not required by an assignment.

A one sample, chi square test was conducted to assess whether concept mapping is deemed useful across the learning styles. The results of the test were significant $\chi^{2}$ (1) $=6.40, p=.011$. The observed frequency of respondents stating that concept mapping was helpful of 9 was much more than the expected frequency of 5 , while the observed frequently of those who do not find concept mapping helpful was much less than the expected frequency of 5. These results indicate that concept mapping is helpful in understanding complex concepts across learning styles. However, it also must be noted, based on descriptive statistics participants do not pursue this method of learning without being directed to do so.

\section{Discussion}

It is imperative for nursing educators to incorporate new active learning strategies to ensure students master the ability to think critically and apply conceptual learning in high stress environments. ${ }^{[7]}$ Research supports student's increased ability to think independently, identify relationships, and develop confidence in their knowledge obtainment when using concept mapping. ${ }^{[8]}$ Although concept mapping is a valuable tool that encourages higher level thinking, it is not the solution to help student understand complex topics. It has been found that affinity for concept mapping is not impacted by learning style preference. ${ }^{[9,10]}$ This conclusion was also supported by the results of this study. It appears that the tool is not specifically attractive to one learning style but appreciated by most.

\subsection{Limitations}

Students were asked to self-identify their learning style based on their completion of the VARK questionnaire. It is possible students did not complete the questionnaire and selfidentified their learning style. Clayton ${ }^{[7]}$ found that although much research exists identifying concept mapping as an effective teaching tool, there has not been enough research done to draw widespread conclusions. It also must be noted that due to the small sample size, this study must be replicated to increase support of these findings. In addition, the convenience sample consisted completely of females. There may be gender differences regarding the affinity for concept mapping that should be further explored. Graduate nursing students were also included within this study limiting its applicability to graduate level nursing students.

\subsection{Implications and recommendations}

Much research exists supporting the use of concept mapping as an active learning strategy used to promote complex learning and critical thinking hence supporting its use in academia. Although there is a perceived benefit to concept mapping, other modes of knowledge obtainment should be explored to promote critical thinking. ${ }^{[5]}$ More research studies need to be done to explore which learning strategies work best with individual learning styles in the effort to promote individualized student centered learning.

\section{CONFlicts OF INTEREST Disclosure}

The author declares that there is no conflict of interest statement.

\section{REFERENCES}

[1] Yeo CM. Concept mapping: A strategy to improve critical thinking. Singapore Nursing Journal. 2014; 41(3): 2-7.

[2] Maneval RE, Fiburn M, Deringer S, et al. Concept mapping: Does it improve critical thinking ability in practical nursing students? Nursing Education Research. 2011; 32(4): 229-233.

[3] Jaafarpour M, Aazami S, Mozafari M. Does Concept Mapping Enhance Learning Outcome of Nursing Students. Nursing Education Today. 2016; 36: 129-132. PMid:26383908 http://dx.doi.org $/ 10.1016 / j$.nedt. 2015.08.029

[4] Harrison S, Gibbons C. Nursing Student Perceptions of Concept Maps: From Theory to Practice. Nursing Education Perspectives. 2013; 34(6): 395-399. PMid:24475601 http://dx.doi.org/10. $5480 / 10-465$
[5] Pudelko B, Young M, Vincent-Lamare P, et al. Medical Education. 2012; 46: 1215-1225. PMid:23171264 http://dx.doi.org/10. $1111 /$ medu. 12032

[6] Leite WL, Svinicki M, Shi Y. Attempted Validation of the Scores of the VARK: Learning Styles Inventory With Multitrait-Multimethod Confirmatory Factor Analysis Models. Educational and Psychological Measurement. 2010; 70: 323-339. http://dx.doi.org/10. $1177 / 0013164409344507$

[7] Clayton L. Concept Mapping: An effective, active teaching-learning method. Nursing Education Perspectives. 2006; 27(4): 197-203. PMid:16921805

[8] Harpaz M, Balik C, Ehrenfeld M. Concept Mapping: An Educational Strategy for Advancing Nursing Education. Nursing Forum. 2004; 
39(3): 27-30. http://dx.doi.org/10.1111/j.0029-6473.20 $04.00027 . \mathrm{x}$

[9] Kostovich C, Poradzisz M, Wood K, et al. Learning Style Preference and Student Aptitude for Concept Maps. Journal of Nursing Educa- tion. 2007; 46(5): 225- 231. http://dx.doi.org/10.1111/j.0 $029-6473.2004 .00027 . x$

[10] Ramprogus V. Learning how to learn in nursing. Nurse Education Today. 1988; 8: 59-67. http://dx.doi.org/10.1016/0260-6 $917(88) 90002-0$ 